\title{
Physical and electrical characteristics of NiFe thin films using ultrasonic assisted pulse electrodeposition
}

\begin{abstract}
Nickel iron $(\mathrm{NiFe})$ thin films were prepared on the copper substrate by ultrasonic assisted pulse electrodeposition under galvanostatic mode. Careful control of the thin films deposition is essential as the electrical properties of the films could be greatly affected, particularly if low quality films are produced. The preparation of $\mathrm{NiFe} / \mathrm{Cu}$ thin films was aimed to reduce the grain size of NiFe particles, surface roughness and electrical resistivity of the copper substrates. Various parameters were systematically studied including current magnitude, deposition time and ultrasonic bath temperature. The optimized conditions to obtain NiFe permalloy, which subsequently applied to all investigated samples, were found at a current magnitude of $70 \mathrm{~mA}$ deposited for a duration of 2 min under ultrasonic bath temperature of $27{ }^{\circ} \mathrm{C}$. The composition of $\mathrm{NiFe}$ permalloy was as close as $\mathrm{Ni} 80.71 \%$ and $\mathrm{Fe} 19.29 \%$ and the surface roughness was reduced from $12.76 \mathrm{~nm}$ to $2.25 \mathrm{~nm}$. The films electrical resistivity was decreased nearly sevenfold from an initial value of $67.32 \mu \Omega \mathrm{cm}$ to $9.46 \mu \Omega \mathrm{cm}$.
\end{abstract}

Keyword: $\mathrm{NiFe} / \mathrm{Cu}$ thin films; Pulse electrodeposition; Surface morphology; Electrical characteristics 